\title{
APOLOGY STRATEGIES EXPRESSED BY THE CHARACTERS IN THE PROPOSAL MOVIE
}

\author{
Amatullah Nabilah ${ }^{1}$, Nuraziza Aliah ${ }^{2}$ \\ State Islamic University of Sunan Ampel Surabaya ${ }^{1}$, Universitas Negeri Makassar ${ }^{2}$ \\ nab.nabilah@gmail.com ${ }^{1}$, zee.aliah@yahoo.com ${ }^{2}$
}

\begin{abstract}
This research is based on the fact that mistake may occur in human interaction. To minimize its effect, the interlocutor needs to apologize to his/her counterparts. This research focuses on the apology strategies, namely the ways of expressing apologies and the social functions of the apologies in "The Proposal" movie. Descriptive research is applied to investigate the phenomenon of apology. The data were verbal and nonverbal apology expressions taken from the English transcript of the movie. The researcher found 32 data containing apology expressed by the characters. An expression of regret comes as the dominant strategy, direct apologies are expressed more than the indirect ones and assuaging the addressee's wrath is the most dominant function of the apologies. Even though making mistakes or offence is unavoidable in human communication, by expressing an apology, the speaker will be able to minimize its effect, solve the problem, and restore the threatened relationship.
\end{abstract}

Keywords: apology; apology strategies; functions of apologies; politeness; "The Proposal" movie

\section{INTRODUCTION}

Deep analysis about the phenomenon of apology is needed because every person may make mistakes in communication. Such a mistake may spoil the relationship between speaker and hearer. In order to maintain harmonious relationship, making mistake should be followed by performing an apology. Olshtain and Cohen (in Wolfson \& Judd, 1983:20) explain that the act of apologizing occurs when the behavior has violated social norm and it requires an action or an utterance that is intended to "set the right". Leech, furthermore, defines that the social goal of apologizing is to restore equilibrium between speaker and hearer (1983:125).

The way people apologize to others is unique and every person has different ways of performing an apology. In apologizing, people should employ some strategies in order to make an apology effective. These strategies of apology which normally occur in real life conversation also exist in various forms of communication, one of which is the movie. This is because movie is a representation of real life.

The phenomenon of apology in real life conversation has been studied by several researchers with various focuses. The cross cultural studies compare an apology in English and other languages (see for example, Yi, 2006; Chamani \& Zareipur, 2010; Aydin, 2013), single language (Dementer, 2000; Shariati \& Chamani, 2010; Banikalef, et al., 2015), and 
across gender (Juhana, 2011; Fitriani, 2012; Chunlin, 2013; Ghanbari, et al., 2014; Majeed \& Janjua, 2014).

Besides, there are some previous researches about apology which take movie as a source of data, such as written by Soesilowati (2009), Riyani (2010), Nikmah (2012) and Ilmah (2015). This present research is different from the previous researches in term of scope of the research. In this research, the researcher also analyzes the social functions of apologies when none of the previous ones did it. Social function has a big influence in apologizing act because every person expressing apology has different purposes to achieve. By investigating the social functions of apology, the researcher is able to reveal the purposes to be achieved by each character in the movie.

Based on the phenomena above, it is interesting to analyze apology as one of the manifestations of being polite. This research focuses to find the answers to the following questions: What are the apology strategies expressed by the characters in The Proposal movie? What are the ways applied by the characters in expressing apologies in the movie? And what are the social functions of apologies expressed by the characters in the movie?

This movie is chosen because it shows various apologies expressed by the characters, hence data of the research were abundant. This research is expected to enlarge the understanding of the use of apology strategies in daily conversation and show the reader the importance of asking apology in order to maintain the harmonious social relationship. The researcher hopes that this research can be useful not only for people in linguistics field but also for people in various fields.

\section{REVIEW OF LITERATURE}

\subsection{Politenes}

Politeness strategy is one of communication strategies of how to act and speak appropriately to others. Politeness implies choosing good words, showing respect, and showing awareness of the hearer's face. Holmes states that generally speaking politeness involves taking account or concern about the feelings of others (1992). Politeness strategy has a correlation with "face" because the function of politeness is to save the hearer's face. Brown and Levinson define "face" as the public self-image that every member wants to claim for himself (1987:61).

Certain speech act can damage or threaten another person's face known as Face Threatening Acts (FTA). Brown and Levinson (1987:101) explain that there are two kinds of politeness strategy in order to reduce FTAs, they are, positive politeness strategy and negative 
politeness strategy. Positive politeness strategy is showing awareness of the hearer's face when they are socially close or know each other well. It is used to lead the speaker to appeal a common goal and friendship. While negative politeness strategy is showing awareness of the hearer's face when they are in the social distance. It is used to show that the speaker respects the hearer and recognizes that they are in some way imposing on them.

Apology is one of the acts that indicate politeness. Based on the explanation above, apology can be considered as positive politeness when the speaker concerns for the hearer's well-being, needs, interests, feelings, and so on. Meanwhile apology can be a negative politeness strategy when the speaker indicates his/her reluctance to impinge on the hearer's negative face.

\subsubsection{Apology}

Apology is an act of asking forgiveness performed by speaker to hearer for the mistake or offence that has been made, such as hurting or making someone injured, offending someone's feeling, or forgetting an appointment. These mistakes can spoil relationship. Therefore, the offender should take the responsibility by asking for an apology. Apology must be delivered politely and sincerely.

Searle (1969 in Trosborg, 1995:373) defines that apology is the effect of paying off the debt from the speaker and compensation for the hearer as the victim for the injury and hurt done by the mistake and offence. Meanwhile, Olshtain and Cohen (in Wolfson \& Judd, 1983:20) explain that the act of apologizing occurs when the behavior has violated social norm and it required an action or an utterance that is intended to "set the right" or to restore the harmonization between speaker and hearer.

\section{Apology Strategies}

Performing an apologizing act requires the speaker to employ some strategies. These strategies help the speaker to make the apology effective and retain a good relationship. These apology strategies can be expressed in simple or complex forms. Simple form means the speaker uses one strategy of apology. Meanwhile, complex form means the speaker uses more than one strategy of apology. The choice of simple or complex form of apology strategies depends on the severity of the mistake and offence. Olshtain and Cohen (in Wolfson \& Judd, 1983:22-23) describe five strategies and sub strategies of apology. They are an expression of an apology, an explanation of account of the situation, an acknowledgement of responsibility, an offer of repair and a promise of forbearance.

An expression of an apology is the most common strategy used by the speaker. It is a strategy to show that the speaker realizes and regrets the mistake that has been made. This 
strategy consists of some ways, they are: an expression of regret, an offer of apology, a request for forgiveness, an explanation of account of the situation, and an acknowledgement of responsibility.

An expression of regret is used when the speaker realizes and feels regret for the mistake s/he has made. For example: "I'm sorry for cancelling our meeting yesterday" or "I regret that I had to postpone our dinner last night". An offer of apology is used by the speaker to make a bid of the apology to the hearer for the mistake and offence. For example: "I apologize for my mistake" or "Please accept my apologies for breaking your favorite vase". A request for forgiveness is used by the speaker to ask forgiveness from the hearer. The speaker asks to be forgiven because s/he has made a mistake. For instance, "Excuse me", "Please forgive me", "Pardon me" or "I'm begging for your forgiveness".

An explanation of account of the situation is used when the speaker explains the situation and reason that cause the mistake or an explanation why s/he makes the mistake to the hearer. For example: "The bus was delayed", "The traffic jam was so bad" or "I got up late" may be said by an employee for being late. And last, an acknowledgement of responsibility is chosen by the speaker only when s/he recognizes the responsibility for the mistake.

This last strategy consists of some ways, they are: accepting the blame, expressing selfdeficiency, recognizing the other person as deserving apology, expressing lack of intent, an offer of repair, and a promise of forbearance (Olshtain and Cohen in Wolfson \& Judd, 1983).

Accepting the blame is an acknowledgement of responsibility used by the speaker when s/he admits and accepts the responsibility for the mistake. For examples "It is my fault", "I know I make a terribly mistake" or "It is my entire mistake". Expressing self-deficiency is used by the speaker to defend her/himself. S/he makes an excuse to cover the mistake and offence. For example: "I was confused," "I was not thinking," "I did not see you," or "I did not do anything."

Recognizing the other person as deserving apology is used by the speaker when s/he realizes that someone deserves an apology. S/he shows the responsibility by recognizing the blame. For instance, "You are right," "You are right to be angry," or "You deserve my apology". Expressing lack of intent is used by the speaker when s/he lacks intent to express an apology. It is not wholehearted apology to the hearer. For example, "I did not mean to," "I'm sure it will clean soon," or "I did not do it on purpose." An offer of repair is used by the speaker only if there is physical injury or other damage that has been resulted by mistake or offence. The speaker repairs, replaces or does other things as compensation for the injury or damage. For example, "I'll pay for the broken vase," "I'll help you get up" or "I'll replace 
your glasses." And, a promise of forbearance is used when the speaker makes a promise to the hearer not to repeat the mistake or to avoid the mistake. For example, when someone forgets an appointment with a friend, s/he might say “It won't happen again" or "I promise I won't be late for the next meeting."

\section{The Ways of Expressing Apology}

There are two ways that can be used by speaker to express apology, namely direct apology and indirect apology (Trosborg, 1995:376). Direct apology means of an explicit apology using one of the verbs signaling an apology. The verbs of direct apology are "apologize", "be sorry", "forgive", "excuse," "fault" and "pardon." For example: "I'm sorry for leaving you" or "Pardon me for this incident".

Indirect apology means an implicit apology or there is an absence of verbs signaling apology and replaced by words and sentences to represent apology, such as taking on responsibility or offering a repair. For example: "The traffic was so bad," "I'll pay for the laundry" or "It won't happen again."

\section{Social Functions of Apology}

The social function of apology refers to the specific purposes of apology used by speaker. Norrick (1978 in Torsborg, 1995:378) describes five specific social functions of apology used by speaker. They are: implicating contrition, asking to be forgiven, showing good manner, assuaging the addressee's wrath, and getting off the hook.

Implicating contrition is a social function of apology when the speaker realizes a mistake. This is to show the guilty feeling and sadness because of the mistake made to the hearer. The speaker is also ready to be responsible for it. Asking to be forgiven is done when the speaker realizes a mistake or offence and asks to be forgiven by the hearer. The speaker might do a serious mistake or offence that needs the hearer to forgive her/him.

Showing good manner is used to show a good behavior or manner for the mistake because the speaker does not want to be considered negative by people. This is based on the reason that when someone makes a mistake, s/he is usually considered negative by people. Assuaging the addressee's wrath is used to minimize the hearer's anger when the speaker makes a serious mistake or hurts feeling that makes the hearer angry. This is because anger is the most severe reaction of the hearer. Getting off the hook is used by the speaker to minimize the rigidity that usually happens between the speaker and the hearer after the mistake is made. This is used to release oneself from an awkward situation and restore harmony between both sides. 


\subsection{Context}

Analyzing a communication should always be related to its context. We cannot judge a communicative intent without knowing the condition when the communication occurs. We have to know the context of a communication because the same utterance may convey different meanings when the context is different.

According to Leech (1983:13), context deals with relevant aspects of the physical or social setting of an utterance. It includes the background knowledge of the utterances shared by the speaker and interpreted by the hearer. Cutting (2002:3) thinks the same way. He defines that the meaning of a conversation depends on the knowledge shared by both the speaker and the hearer. He also divides context into three categories: situational context, background knowledge context, and co-textual context. Malinowski (in Halliday \& Hasan, 1985:6) coined two kinds of context, namely context of situation and context of culture. Context of situation refers to the environment where the utterance is produced, whereas context of culture to the background culture of the speaker and the hearer. The background culture can be the people, time, social condition, and political background.

\section{RESEARCH METHODS}

This is a descriptive research because this research is trying to reveal the natural phenomena of apology. Descriptive research is a design to obtain precise information concerning the current status of phenomena and to draw valid conclusion from the facts discovered (Chandra \& Sharma, 2007:263). The data source was the English subtitle of The Proposal movie. The data were the verbal apology which consists of dialogues and utterances in the form of words, phrases, and sentences that indicate the use of apology complemented with nonverbal expressions such as: body language, facial expression, smile, eye contact, touching, and intonation. The key instrument of this research was the researcher because it needs some interpretation from the researcher herself.

The data were collected by some steps. After printing out the English subtitle of the The Proposal movie, the researcher sorted out the characters' utterances that consist of apologies by underlining them. Then, the researcher analyzed the data by first developing some codes, assigning the codes to the identified data, classifying the data, interpreting the data, and the last making a conclusion. 


\section{RESULTS AND DISCUSSIONS}

\subsection{Results}

\subsubsection{Apology Strategy}

The researcher found 32 data containing apology strategies in The Proposal movie. The result is presented in three parts. The first part is apology strategies, the second part is the ways of expressing apologies, and the last part is the social function of the apologies.

The following chart shows the use of apology strategies by characters in The Proposal movie.

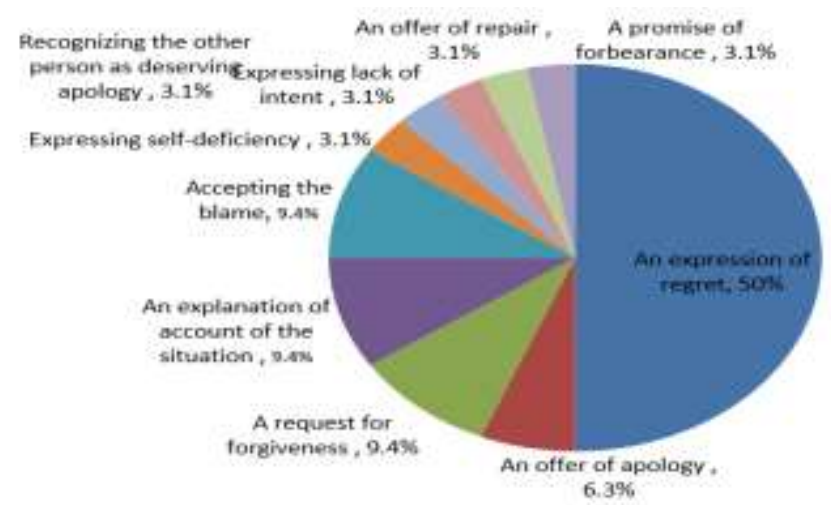

Figure 1. The Use of Apology Strategies by Characters in the Movie

Based on the data analysis, the figure above shows that the characters in The Proposal movie use all of the apology strategies. Expression of regret which is $50 \%$ of use in proportion to all uses of apologies is the most dominant strategy. It implies that the characters in that movie mostly express their apology to show regretful and guilty feelings of their mistakes. Then, three strategies in the second highest number are requesting for forgiveness, accepting the blame, and an explaining of account of the situation. Each of them occurs 3 times out of 32 data (9.4\%). The third highest number of the apology strategies is an offer of apology (6.3\%). The remaining strategies come as the lowest strategies, they are, expressing self-deficiency, recognizing the other person as deserving apology, expressing lack of intent, offering repair and promising forbearance (3.1\% each).

Here is one of the examples of an expression of regret strategies in The Proposal movie.

Excerpt 1

Andrew : Sweet...

Worker 1 : Uh, sorry.

Andrew : Jesus!

Worker 2 : Rub some dirt on it, brother. (Data 1/18)

The conversation above happened between Andrew and another worker. Andrew entered his office in the morning while holding two cups of coffee. He was in a hurry because he was 
almost getting late. When he was walking, he accidentally collided with another worker who was pulling a trolley. The collision made one of the coffees spilled and left dirt on his shirt.

The utterance "Uh, sorry" used by the worker is to deliver his apology to Andrew. "Uh, sorry" is to an expression of regret in an apology strategy. The utterance "Uh, sorry" expressed by the worker is to show the feeling of regret because of his fault in making one of Andrew's coffee spilled and left dirt on his shirt. The low tone of the worker's voice when he expressed his apology indicates that he really felt regretful of his mistake. Even though it happened in the office the conversation between Andrew and another worker was informal. Andrew and the worker are not in a close relationship even though they work in the same office. In this datum, the worker used negative politeness strategy to indicate his awareness of having impinged on Andrew's negative face.

\subsubsection{The Ways of Expressing Apologies}

The ways of expressing apologies used by the characters are divided into direct apology and indirect apology. The data classification is presented below.

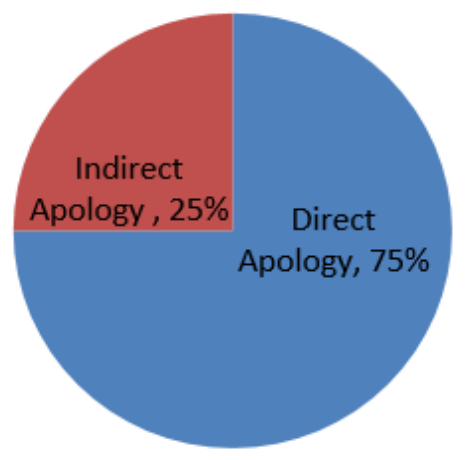

Figure 2: Ways of Expressing Apologies

Based on the data analysis, the characters in "The Proposal" movie express their apology in both ways and direct apology is mostly used by the characters. Direct apology takes three quarters which is 24 times out of 32 data or $75 \%$ of the total apologies. While indirect apology takes a quarter which appear 8 times out of 32 data or $25 \%$ of the total apologies.

Here is one of the examples of direct apology in The Proposal movie.

Excerpt 2

Mr. Jack : Margaret. We are desperate to have you stay. If there was any way, any way at all that we could make this work, we'd be doing it.

Margaret : There is no way... I am begging you. (Andrew knocked then opened the door)

Mr. Jack: No, Margaret. Excuse me, we're in a meeting. (Data 5/200) 
This conversation happened between Mr. Jack and Margaret when they were in the middle of a meeting. Suddenly, Andrew knocked and opened the door. An utterance "Excuse me, we're in a meeting." shows a direct apology from Mr. Jack to Andrew. The word "Excuse me" is one of the verbs signaling an apology. In this conversation Mr. Jack delivered an apology because he could not allow Andrew to come in the room because he was still in a meeting with Margaret. Mr. Jack used negative politeness strategy to indicate his awareness of imposing on Andrew's negative face.

\subsubsection{The Social Functions of Apology}

The results of the data analysis on social functions of apology show the presence of five functions in the characters' apologies, they are, implicating contrition, asking to be forgiven, showing good manner, assuaging the addressee's wrath, and getting off the hook. The data classification is presented below.

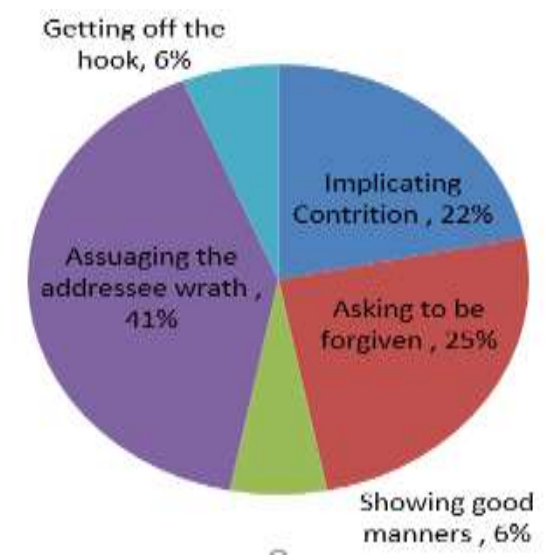

Figure 3: Social Functions of Apology

Based on the data analysis, the figure shows that the characters in The Proposal movie apply the apology strategies for all social functions. Minimizing the addressee's anger is the most dominant function intended by the characters. It occurs 13 times out of 32 or $41 \%$ of the total functions. The second highest function is asking to be forgiven (25\%) followed by implicating contrition in the third highest function (22\%). The last two functions are showing good manner, and getting off the hook; each appears twice or $6 \%$ of the total functions.

Here is one of the examples of implicating contrition or regret function in the movie.

Excerpt 3

Joe Paxton : I need you to quit playing around...

Andrew : Here we go again. When are you going to start taking what I do seriously?

Joe Paxton : When you start acting seriously.

Andrew $\quad$ : I'm sorry. I feel sorry for you, Dad. I wish you had another son. I really do. One who wanted to stay here. One who wanted to take 
over the family business. (Data 18/896)

That conversation happened between Andrew and his father, Joe Paxton. Joe wanted his son to stop playing around, back in their home and continue the family business. But, Andrew was thinking about it differently. He thought that being an editor in New York was his dream.

Andrew delivered an apology to his father by an utterance " $I$ ' $\boldsymbol{m}$ sorry. I feel sorry for you, Dad". The function of his apology is to show regretful feeling. Andrew showed his sadness because he could not be a son as his father wanted. His expressions in the next sentence "I wish you had another son. I really do. One who wanted to stay here. One who wanted to take over the family business" indicate his wish that his father had another son who can do what his father wants, such as, staying in their home and taking over the family business. Andrew used positive politeness strategy when he apologized to Joe because he was concerned about his father's feeling of disappointment.

\subsection{Discussions}

Apology is one of the important parts in our daily communication. It is likely done by the people who make mistakes and offences while having a conversation with others. Apology in communication does not only occur in real life communication but also in various other communication media, such as a movie. This is because a movie is the representation of real life.

The researcher found that out of the five strategies and sub strategies of apology, an expression of regret comes as the highest strategy used by the characters. It means that most of the characters expressed apology to show their guilty feelings and to regret of their mistake. The choice of apology strategies depends on the context of the situation, degree of mistakes, and the social status and relationship between speaker and hearer. One of the influences of expressing apology strategies is by the context of the situation. Most of the apology occurring in The Proposal movie is in informal situation and the setting is in the house. The dominant strategy used in this movie is an expression of regret and the word "sorry" is mostly uttered by the characters to express an apology.

This is different from Riyani's research (2010) which examined apology strategies in the Pride and Prejudice movie. This movie is in formal situation which consists of upper and middle classes. That is why her finding shows the dominant strategy expressed by the characters in that movie is a request for forgiveness with expressions like "Excuse me", "Please forgive me", "Pardon me" and "I'm begging your forgiveness" (Riyani, 2010). These verbs of apology are usually used in formal situations to respect the hearer. Insofar as the 
source of data is a movie, the findings of this research confirm an idea that one of the factors of using apology strategies is determined by the context of the situation in the movie itself.

The characters in this movie express their apology not only directly but also indirectly. The characters in The Proposal movie dominantly utter direct apologies by using the verbs signaling apology, such as "apologize", "be sorry", "forgive", "excuse", "fault" and "pardon" more than that of indirect apology with the absence of verbs signaling apology and replaced by words and sentences to represent their apologies. This research has the same finding with Soesilowati's (2009), Nikmah's (2012), and Ilmah's (2015) researches which show that direct apologies are bigger in number than the indirect apologies. Direct apologies are mostly uttered because in expressing an apology people tend to be straight to the point by uttering "sorry" or "apologize" rather than using other words or sentences such as explaining the situation or offering a repair. This direct way of expressing an apology may be more effective because the hearer does not need longer time to perceive and comprehend the intention of the speaker when the mistake has just occurred.

The researcher also found that out of the five social functions of apology, reducing the addressee's anger is dominantly uttered by the characters. Assuaging the addressee's anger is the most dominant because anger is the most frequently appearing reaction of the hearer when the speaker makes a mistake.

Regarding the fact that apology is one of the examples of politeness, apology can occur in positive and negative politeness. Apology as positive politeness strategy concerns about the addressee's feeling; while apology as a negative politeness strategy indicates the speaker's reluctance to impinge on the hearer's negative face. The data in this research show that apology as a negative politeness occurs more than apology as a positive politeness.

Finally, the researcher would like to discuss apology in Islamic point of view. Asking for an apology is closely related to giving forgiveness. When the speaker makes a mistake, s/he should directly follow it by apologizing to the hearer. In Islam, when someone apologizes, there is no reason for the hearer not to forgive. It is even required that forgiving must be given regardless of apology. The act of forgiving is stated in the Holy Qur'an Surah Al-Baqarah: 263 as well as in a Hadits of the Prophet Muhammad (PBUH) which tell us to forgive or accept apology from others. The Surah and Hadits suggest that we should always forgive or accept the apology of others even before the speaker asks for it. Even though we do not know whether or not the apology is sincere, forgiving is our obligation as Muslims. Forgiving is the character of a true Muslim and its doer gets reward from Allah SWT. Apology and 
forgiveness are effective ways to maintain good relationship among human beings and the best way to establish social harmony.

\section{CONCLUSION}

The researcher concludes that apology is an important thing in communication because human is likely to err, to make mistake and offend other people. Some strategies of apology should be applied by the speaker in order to make the apology effective. In conclusion, even though as a human being we cannot be free from making mistake or offence in a communication, by expressing an apology we will be able to avoid the clash, solve the problem, and restore the broken relationship. The researcher recommends for the next researcher to focus their research of apology on different media, such as real life conversation, novel, drama, talk show, newspaper, social media, and so on. The future researchers can also focus their research on apology in different area in the society, such as, students' apology toward their lecturer or their peers, or apology used by members of a community in view of power relation.

\section{REFERENCES}

Aydin, M. (2013). Cross cultural Pragmatics: A study of Apology Speech Acts by Turkish speakers, American English Speakers and Advance Nonnative Speakers of English in Turkey. (Thesis, University of Minnesota, 2013).

Banikalef, et al.. (2015). Apology Strategies in Jordanian Arabic. Journal of Language Studies, Vol.15 (2), 83-99.

Brown, P. \& Levinson S.C. (1987). Politeness: Some Universals in Language Usage. Cambridge: Cambridge University Press.

Chamani, F. \& Zareipur, P. (2010). A Cross-Cultural Study of Apologies in British English and Persian. Studies in Linguistics, 36.1, 133-153.

Chandra, S.S. \& Sharma, K.R. (2007). Research in Education. India: Atlantic Publishers \& Distributors (P) LTD.

Chunlin, Y. (2013). Males and Females in Making Apologies in Chinese Daily Conversations: the Differences and the Similarities? International Journal of Social Science and Humanity, Vol. 3 No. 3, 268-273.

Cutting, J. (2002). Pragmatics and Discourse. New York: Routledge.

Dementer, G. (2006). A Pragmatic Study of Apology Strategies in Romanian. (Thesis, University of Oklahoma, 2006). 
Fitriani, N. (2012). Apology Strategies: Are Women's Different from Men's? Retrieved June29, 2009 from http://repository.perbanas.id/xmlui/bitstream/handle/123456789/378/Nani_Fitriani_APO LOGY_STRATEGIES.pdf?sequence=1

Ghanbari, et al.. (2014 November 27-28). Investigating Apology Strategy among Male and Female Kurdish Bilinguals at Ilam. Paper presented at 2nd Global Conference on Psychology Researches. Iran.

Halliday, M.A.K. \& Hassan, R. (1985). Language, Context, and Text: Aspects of Language in Social-Semiotic Perspective. Hongkong: Oxford University Press.

Holmes, J. (1992). An Introduction to Sociolinguistics. UK: Longman Group Ltd.

Ilmah. K. (2015). The Acts of Apology Strategy used by the Characters in the "Stuart Little 2" Movie. (Thesis, State Islamic University Sunan Ampel Surabaya, 2015).

Juhana. (2011). The Use of Apologizing Speech Acts Realization by Male and Female Students. Ragam Jurnal Pengembangan Humaniora, Vol.11, No 1, 1-10.

Leech, G.N. (1983). Principles of Pragmatics. New York: Longman.

Majeed, A. \& Janjua, F. (2014). Apology Strategies and Gender: A Pragmatic study of apology speech acts in Urdu language. Merit Research Journal of Education and Review, Vol.2 (3),054-061.

Nikmah, M.T. (2012). Analysis of Apology as a Politeness Style of Expressed by the Characters in the Twilight Saga Movie (Thesis, State Institute of Islamic Studies Salatiga, 2012).

Norrick, N. R. (1978). Expressive Illocutionary Acts. In: Anna Trosborg, Interlanguage Pragmatics; Request, Complaints and Apologies (376).New York: Mouten de Gruyter.

Olshtain, E. and Cohen A.D. (1983). Apology: A speech Act Set. In: Nessa Wolfson and E. Judd (ecls), Sociolinguistics and Language Aquisation. Rowley (22-23). MA: Mewbury House.

Riyani, I.D. (2010). Apology Strategies Used By the Characters of Joe Wright's Pride and Prejudice Movie. (Thesis, State Islamic University Maulana Malik Ibrahim, 2010)

Searle, John R. 1969. Speech Acts: An Essay in the Philosophy of Language. Cambridge: Cambridge University Press.

Shariati, M. and Chamani, H. (2010). Apology Strategies in Persian. Journal of Pragmatic. 42, 1689-1699.

Soesilowati, R. (2009). An Analysis Of Apology As A Politeness Strategy Expressed By The Characters In The Film Entitled "Chasing Liberty (Thesis, Sebelas Maret University Surakarta, 2009). 
Trosborg, A. (1995). Interlanguage Pragmatics; Request, Complaints and Apologies. Berlin; New York: Mouten de Gruyter.

Wolfson, N. and Judd, E. (1983). Sociolinguistics and Language Acquisition, Rowley MA: Newbury House Publishers Inc.

Yi, L. (2006). A Comparison of Apology Strategies in Chinese and English. (Thesis, University of Hongkong, 2006). 